\title{
Food Safety Control from the Perspective of Supply Chain
}

\author{
Weiyan Xie \\ Guangxi Vocational College of Technology and Business, Nanning, 530008, China
}

\begin{abstract}
In view of China's rapid economic development, people are increasingly more concerned about food consumption and especially food quality and safety and thus have new requirements for food safety control, and Chinese food supervision also develops from previously simple food certification into today's certification of food management system. However, China's existing food safety system is still imperfect. Thus, new concepts of supply chain management shall be introduced and countermeasures shall be taken actively to establish a system that guarantees food safety control. This paper analyzes the relationship between supply chain management and food safety, and puts forward food safety control strategies under supply chain management.
\end{abstract}

Key words: supply chain, management, food safety control

Along with sustainable development of Chinese economy, modern people have an increasing living and consumption ability. Consumers' concern changes from food availability and diversity into quality and safety, and their food consumption behavior also changes from great sensitivity to prices into extreme sensitivity to safety. However, constant food safety problems in real life make consumers lack confidence in food safety. Thus, it is very necessary to apply supply chain management means.

\section{The relationship between supply chain management and food safety}

The so-called supply chain management mainly refers to a management mode which is generated by enterprises' application of modern information technology based on a lot of modern management concepts in order to meet requirement of today's diversified supply and demand market for organization and management flexibility and efficiency. Supply chain is actually a business process model that mainly includes two categories, namely internal and external supply chain management. The former mainly refers to raw material purchasing, manufacturing and distribution etc within production department; while the latter mainly refers to many links including raw material production staffs, manufacturing staffs, sales staffs, and finished product consumers etc. As one of novel management means, supply chain management has mainly the following performances: firstly, it establishes systematic concepts, and no longer treats simply relationships among departments and external relationships, but considers about all related internal and external relationships; secondly, it has common goals, and makes clear final receivers of products and services, i.e. consumer demand inevitably becomes a common performance goal of all participants in supply chain management; thirdly, it carries out positive management, and requires active intervention in full participation in supply chain management, so that source management is no longer an auxiliary link that is not important in food production but becomes one of important links of implementing quality requirements; and fourthly, it promotes information sharing under cooperation system, as it could only be implemented under extremely good information sharing conditions and would have declined performance especially under risks caused by 
sharing of bad information. So, product quality and service ability can be better enhanced if supply chain management participants including consumers are involved in information exchange mechanism. Nowadays, food safety has become a global difficulty and focus. Although ISO9000 series has been widely applied to production, management and sales of food processing industry, it is after all one of universal management methods and cannot conduct comprehensive and meticulous management of the entire industry.

\section{Food safety control strategies under supply chain management}

(I) Establish a supply chain partner alliance to practically guarantee food safety

Participants in supply chain management can gain corresponding benefits through circulation of materials and information. Value of commodities shall be reflected through use value. Only qualified and safe finished food can really realize overall benefits of supply chain management. It should be said that corresponding subjects of food supply chain management have interconnected benefits. Safe food could enhance overall benefits of supply chain management. On the contrary, food safety problem caused by each participant would lead to big loss of supply chain management. For example, pork luncheon meat produced by a well-known Chinese meat processing enterprise was found to contain clenbuterol in selective inspection of quality control department. Upon public notification, its stock price declined significantly immediately, causing huge loss. So, the development goal of food supply chain management is overall benefits, the carrier and foundation of which is exactly food safety. In Chinese food supply chain management, consumers get food after small-scale production and operation by scattered peasants, and then production and processing in agricultural processing enterprises, and finally sales by a large number of unfixed dealers and retailers. Such very scattered organizations face huge costs of food safety control and thus always lack sufficient and effective control and restriction of behaviors that threaten food safety. To practically guarantee food safety and realize overall rights and interests of supply chain management, it is currently urgent to establish a partner alliance based on supply chain management, so as to achieve mutual coordination and finally reach benefit integration. For this reason, partner alliance in food supply chain management shall be fully considered, i.e. take large-scale food processing companies with strong market competition strength as core link of supply chain and leading party of this alliance. It shall train organizational modern agricultural production department actively in upstream market, and form a main supply base of agricultural products and raw materials; strive to establish mature and stable distribution channels in downstream market, and find appropriate dealers and retailers. Of course, this partner alliance can finally be maintained by relying on contractual relations. Contracts shall specify food quality very strictly, and clarify responsibilities and interests of each party. This close partner alliance will be positively restricted by common interests of each party, and thus could naturally take effective guarantee measures, realize information sharing and better ensure food safety.

(II) Set up food processing hazard control sites to strictly implement food pre-sale detection mechanism

Although close partner alliance could control effectively food safety problems due to subjective reasons, authoritative detection mechanisms and means shall be carried out in case of problems due to objective reasons such as biological pollution etc. The author believes that the root of biological pollution lies in supply of agricultural materials and initial 
production link of agricultural products. However, if comprehensive monitoring and inspection are conducted with agricultural production period as an important link of hazard control, it would inevitably lead to huge costs and implementation difficulty. Chinese agricultural production is of a highly decentralized small organization, and a quite small amount of planting and breeding as well as many varieties lead to its failure in centralization and standardization. Once specific production behaviors of all production staffs are to be standardized in this context, there would be a lack of practicality of detecting and inspecting production varieties. The author believes that it is completely possible to find out a control site to maximize control and prevention of hazards although food safety cannot be completely achieved, so as to control biological pollution practically in a minimum range. According to actual situation of Chinese agricultural development, food processing links such as slaughter houses and processing enterprises etc shall be hazard control sites. This is because agricultural product processing links are quite centralized, which is conducive to monitoring and convenient for detection and can be controlled and handled well in case of biological pollution. Meanwhile, processing link has relatively greater profitability in food supply chain management system, while economic strength of food processing enterprises can also be applied to measures in terms of food safety control. Supply chain management food safety intervention income model can give great inspiration to hazard control of processing enterprises. For example, by controlling pork salmonella in supply chain management, cost benefits paid for comprehensive safety intervention in slaughter houses would greatly exceed cost benefits that enterprises gain. Meanwhile, prior control shall be strengthened as much as possible in food safety control, i.e. avoid various polluted food from consumption link by all means. In view of extreme proneness of food to secondary pollution in circulation link, food shall be of strict detection and inspection etc before sales and polluted food shall be dealt practically, so as to ensure safe food for consumers.

(III) Give full play to active role of radio frequency identification technology to carry out traceability management of food supply chain

As a non-contact identification technology, radio frequency identification has a variety of advantages, such as large amount of information storage, very quick identification and less proneness to artificial damage of tags etc. Radio frequency identification technology can be applied to trace the entire process of Chinese agricultural products including production, processing, storage and sales etc as well as production and processing etc of various kinds of food, and thus supervision and management of agricultural products can be strengthened more effectively. Specific application of radio frequency identification technology shall be achieved from the source and radio frequency identification tags shall be inserted at the beginning. Firstly, add radio frequency identification tags at sources of food or raw materials through enterprises and write relevant information of food or raw materials in sources, such as place of production, date of production, storage mode, and edible methods etc. Secondly, upon delivery of products from places of origin to food processing enterprises, at which stage, processing enterprises write information after processing or packaging immediately for use of next processing staffs or consumers. Thirdly, local quarantine bureau writes information on quarantine and storage. Fourthly, products are distributed to regional agencies after delivery from storage until sales terminals like supermarkets, catering and restaurants etc, and then the above information would be written in, so as to realize the last important link of 
tracing chain. Food information is written on radio frequency identification tags in above links just like interlocking chains, and finally full information on this food will be formed, which is conducive to food tracing. Fourthly, food of last stage is served for consumers. Many links of food monitoring and management in whole supply chain can be realized by carrying out the entire process mentioned above.

Safety of food supply chain management can be guaranteed by radio frequency identification technology. Radio frequency identification solution can ensure each supply chain to realize high-quality data exchange, so that Chinese food industry can fully achieve two most important development goals as follows: firstly, carry comprehensively out a comprehensive solution to trace source food, and thus ensure safe food sources; and secondly, enable food supply chain management to provide full transparency. Radio frequency identification system doesn't merely use a central computer to record specific positions of each tray or goods box for food, because it could clearly acquire goods boxes in trays and even specific positions, identities, storage records, destinations and other related practical information of various goods. Thus, radio frequency identification system can provide complete and detailed data about actual products in supply chain management, form a physical relationship between goods and complete identities, and ensure that production and operation staffs could record truly specific information concerned by consumers, so as to facilitate query and enable consumers to feel highly responsible attitude of production and operation staffs towards food safety. In case of food safety problems, look up related information recorded in the system to make clear specific reasons in terms of production and operation, clarify whether related products are in storage, transportation or partial sales, take corrective actions actively to make sure responsibilities of related subjects at different stages of supply chain management, and thus reduce worries and panic of consumers. The most important thing of food tracing by radio frequency identification technology is that production and operation staffs shall guarantee that information of current stage meets actual requirements with due diligence. Practitioners of each stage shall truly record information on food or raw materials including goods sources and related information processing etc of this stage, carry on and inherit actively records of production and circulation etc in last link, and take responsibility for these records. To trace food authenticity seriously under circumstances of mixing up truth with falsehood, arbitrary changes of radio frequency identification and tag records etc, trace from downstream gradually to upstream to find out unsafe food and practitioners who violate international law, punish people who break promises according to laws and regulations through product recall system, and safeguard social justice and fairness vigorously. To this end, radio frequency identification is the most ideal solution to full trace of food sources, and is very widely applied in western developed countries at present, and good effectiveness has been achieved.

\section{Conclusions}

To sum up, under unoptimistic food safety situation in current China, establishment of partner alliance based on supply chain management, setting of food processing hazard control sites, and traceability management based on radio frequency identification technology etc are all effective approaches for food safety problems under supply chain management. Occurrence probability of food safety accidents can be reduced practically and effectively by applying the above strategies actively. 


\section{References:}

[1] Zeng Youxin, Liu Haiyan. Food Logistics Management [M]. Beijing: Chemical Industry Press, 2007.

[2] Wu Li. Study on Food Safety Risk Control Mode Based on Supply Chain [J]. Food and Fermentation Industries, 2010 (8).

[3] Chen Yuan. Structure Design of Adaptive System for the Food Safety Management in Food Supply Chain [J]. Journal of Safety Science and Technology, 2011 (1).

[4] Ma Jie. Study on Food Safety Control in the Context of Supply Chain [J]. Modern Business, $2012(5)$.

[5] Zhang Jinli. The Key Points Analysis of Supply Chain Perspective of Food Quality and Safety Control [J]. Logistics Engineering and Management, 2013 (10).

[6] Ge Congli. Food Safety Control Based on Food Supply Chain [J]. China Management Informationization, 2014 (1). 